\title{
COMPOSITION IS NOT RESEARCH
}

\author{
John Croft
}

\begin{abstract}
Composers in academic institutions are increasingly required to describe their activities in terms of 'research' - formulating 'research questions', 'research narratives', 'aims' and 'outcomes'. Research plans and funding applications require one to specify the nature of the original contribution that will be made by a piece of music, even before it is composed. These requirements lead to an emphasis on collaborative work, technology and superficial novelty of format. Yet the very idea that musical composition is a form of research is a category error: music is a domain of thought whose cognitive dimension lies in embodiment, revelation or presentation, but not in investigation and description. It is argued here that the idea of composition as research is not only objectively false but inimical to genuine musical originality.
\end{abstract}

There are, by and large, two kinds of composers in academia today those who labour under the delusion that they are doing a kind of 'research', and those who recognise the absurdity of this idea, but who continue to supervise $\mathrm{PhD}$ students, make funding applications, and document their activities as if it were true. Composing, of course, might on occasion depend on research - how do I make an orchestra sound like a bell? How do I electronically sustain a note from an instrument so that it doesn't sound mechanical? What is the best way to notate microtones or complex rhythms so that they can be accurately played? But none of these is actually the composition of music. Rameau's harmonic theory was research, and it surely influenced his music (and music in general), but the Traité de l'harmonie is not a musical composition. The development of the pianoforte involved research and influenced music in profound ways, but it was not composing.

One might argue that at least the construction of compositional systems is research. Now, even granting this, it would remain the case that good and bad music can be made from any system - so after all the explications of technique, the compositionally important thing would remain unexplained and untouched. But in reality even compositional systems are not research in any strong sense. This is because the answer to any conceivable 'research question' that might be involved is known in advance. Imagine, if you will, a research funding application from Schoenberg. Research question: 'can I make music in which all pitch classes are played equally often?' Answer: yes! Or one from Grisey: 'can I make chords out of the pitches revealed by spectral analysis?' Answer: yes! Can I write 
a piece by sonifying the human genome? Actually, yes! If the answer to your 'research question' is always (trivially) 'yes', then there's no research going on.

But this is in fact what grant applications, composition $\mathrm{PhD}$ abstracts, and the 'research narratives' we are required to write for the 'Research Excellence Framework' (or its equivalents in an increasing number of other countries) tend to look like. Sometimes, as if aware of the problem, we insert an evaluative term: 'can a coherent musical structure be developed from sonification of the human genome?' Without the word 'coherent' the answer is of course yes. So we put something in to make it seem like the result is not a foregone conclusion. But of course it is a foregone conclusion, because what one generally means by such a question is 'can I write convincing music with this technique?' where the person to be convinced is ... me! Can I write music that I think is good? It turns out I can. Now, we could of course conduct research into questions like this: we could, for example, empirically test the perceived cohesion of music constructed in a certain way. But composition in that case would be the test stimulus for a music psychology experiment, not itself research. Alternatively, we might look at how often composers have decided to use certain techniques - but in that case the compositions are data, again not themselves research. Furthermore, if pre-compositional work and system building cannot be classed as research, then it is not possible to avoid this problem by claiming that compositions are in some sense the 'findings' of a research process. Indeed, the bizarre idea that the purpose of a musical composition is to report findings brings into stark relief the category error that is at work here.

I have done it myself many times - I have made up 'research questions' that have nothing to do with composing; specified 'objectives' and 'milestones', outlined the 'collaborative process', knowing full well that what I was in fact planning to do was pick up a pencil, start at the beginning, and stop when the piece is finished - maybe asking the performers a question now and then, or maybe not. ${ }^{1}$ I've even avoided the word 'composing', opting instead for 'investigating', as in 'investigating new techniques and sonorities'. It helps if you can work in some cutting-edge technology as well. The latest thing is 'impact' - nearly impossible to demonstrate in music without focusing on things that are peripheral to it. ${ }^{2}$ The incongruity between the act of composition and the way we are required to portray it has not gone unremarked: the advice you'll receive from a seasoned composeracademic is simply to make up some nonsense to get the money, and then forget the nonsense and write the piece you wanted to write in the first place. The problem with this is not just that funding goes to those most adept at writing nonsense, but that it is hard to avoid at least a passing resemblance between what one says one will do and what one eventually does. If, in order to get some

${ }^{1}$ I discuss the deleterious effects of the institutional obsession with collaboration in 'On Working Alone', in Creativity, Improvisation and Collaboration: Perspectives on the Performance of Contemporary Music, ed. Eric F. Clarke and Mark Doffman (New York: Oxford University Press, forthcoming).

2 Factors like the number of people that hear a piece, and how much they are affected by the music, do not count as 'impact' in the sense required by, for example, the UK's Research Excellence Framework or Arts and Humanities Research Council. But if I write an opera about global warming, and someone does a survey about whether it has 'raised awareness', then that, it seems, is 'impact'. Needless to say, the impact agenda is harmful to many disciplines, and reflects a profound misunderstanding even of how even paradigmatic research progresses. 
funding, I say that I'm going to write a piece about 'sustainability', converting arctic ice cap data into sound files to be manipulated in real time in an internet-mediated free-improvisation event combining live programming, video projection, and social media, and if I get the money and then just compose the ensemble piece I wanted to write in the first place, questions will surely be asked.

Of course, writing the ensemble piece doesn't really need all that money. But in universities today research income has become a proxy for quality. ${ }^{3}$ The effect of this is pernicious enough for activities that are properly described as research; doubly so for musical composition, which now must justify its place in the academy by obtaining money for something it isn't really doing in the first place. This is all part of a more general tendency to outsource qualitative judgement to quantitative measures. This academic commodity fetishism is manifested not just in the humdrum money-grubbing of the modern university, but in the broader culture of accountability that dominates both the academy and arts funding organisations. Who's to judge the originality of musical material? It's all 'subjective', isn't it? But you can't argue with the groundbreaking nature of the polar-ice-based internet improvisation event - nobody's ever done that before! This kind of activity is objectively 'innovative' in a way that you can tell in advance, without going to the trouble of a risky aesthetic judgment.

There is a fundamental distinction at work here: research describes the world; composition adds something to the world. ${ }^{4}$ Research, at least of the scientific kind to which musical composition is generally assimilated, aims to produce generalisable results; the significance of a piece of music lies, on the contrary, in its particularity. This is not to say that music has no cognitive dimension, or that it does not have a kind of truth - only that it does not have the kind of truth that is discovered by research. We might agree with the philosopher Aaron Ridley, who insists that music can have profound truth in virtue of the outlook on reality that it embodies - but that outlook is not a description but an attitude. ${ }^{5}$ Or perhaps, with Schopenhauer, we might think that music reveals something even more profound about the universe; but revelation is also not research. ${ }^{6}$ Or, with Langer, we might emphasise the alignment of music and inner life: music tells us not so much how the world should be described as how it feels. ${ }^{7}$ Or, with Heidegger and Gadamer, we might emphasise the cognitive content of art while insisting on its resistance to conceptualisation - it presents rather than represents, discloses without describing. ${ }^{8}$ In terms of

\footnotetext{
${ }^{3}$ In general, throughout this article, I have in mind the situation in the United Kingdom; but many of these problems are found to varying degrees in other countries, as research assessment exercises and income-based academic 'performance metrics', are adopted, often in imitation of the UK system.

${ }^{4}$ Cf. Gadamer's argument that art does not describe but adds being to the world. (Hans-Georg Gadamer, Truth and Method [1960], trans. Joel Weinsheimer and Donald G. Marshall (London: Continuum, 2004), pp. 135ff.)

5 Aaron Ridley, The Philosophy of Music: Theme and Variations (Edinburgh: Edinburgh University Press, 2004), passim. The idea of music embodying at attitude suggests an affinity with philosophy - a discipline which, like composition, resists accommodation within a model of empirical research, but which, unlike composition, does at least ask questions and attempt to answer them in a discursive manner.

${ }^{6}$ Arthur Schopenhauer, The World as Will and Representation [1844], Vol. I, trans. E.F.J. Payne (New York: Dover, 2000), sections 2 and 3 passim.

7 Susanne K. Langer, Philosophy in a New Key [1941] (Cambridge, MA: Harvard University Press, 2009), pp. 204ff.

8 Martin Heidegger, 'The Origin of the Work of Art' [1950], in Basic Writings, ed. David Farrell Krell (Oxford: Routledge, 2010), pp. 85-139; Gadamer, Truth and Method.
} 
Wittgenstein's famous distinction, such things can only be shown, not told. ${ }^{9}$ Notwithstanding various efforts to dissolve such distinctions, it remains the case that, if Einstein had not existed, someone else would have come up with Relativity. If Beethoven had not existed, nobody would have written the Ninth Symphony.

This example bears further consideration: if Beethoven had not existed, someone would no doubt have added voices to a symphony. Similarly, if Schoenberg had not existed, someone else would probably have come up with the twelve-tone system. Conversely, scientific writings can be as idiosyncratic and unique as works of art. So art is, on some level of generality, 'waiting to happen' before it is made, and, on some level of specificity, research involves matters of style. Robert Root-Bernstein, for example, emphasises this point, only to undermine it by observing that simultaneous discoveries in science are often non-equivalent: 'Mendeleev's period table is not Lothar Meyer's, nor did they make identical predictions. ${ }^{, 10}$ Precisely - and the successful predictions are why Mendeleev's table forms the basis of the one used today, and why Meyer modified his table to be more like Mendeleev's. There is a reason we prefer Darwin to Lamarck, and it isn't one of style. Einstein corrects and supersedes Newton; Schoenberg does not correct and supersede Bach. One can understand Gauss's flux theorem perfectly well never having read a word of Gauss; one cannot understand Debussy's music without ever hearing a note of it. A good theory can be poorly articulated, but there is no such thing as good music badly composed. ${ }^{11}$ The imagination needed for scientific and other research, and the occasional sense in art that there is something waiting to be discovered, should not blind us to this crucial difference. ${ }^{12}$

Suppose that someone had asked Beethoven what his research questions were in the Ninth Symphony. For a start, Beethoven would surely have been mystified, to say the least, by such a demand. But let us try to imagine what he would have come up with, had he been so inclined. Perhaps one might be, how can voices be introduced into the symphony?' The answer, as it turns out, is with a baritone recitative. Now, in a trivial sense, this is of course an answer to the question 'how can voices be introduced into the symphony?, in the sense that anything vocal could be an answer. But in any meaningful sense it is precisely not an answer to the question of how to introduce voices into the symphony; rather, it is an answer to the question of how voices are to be introduced into this symphony, at this particular point, after all that comes before this moment. That is, it is a musical, not a discursive, question, and is asked by the music, not by a research proposal.

This is not to say that music cannot be discussed in language - of course it can, and there are vocabularies and ways of talking about music that do help us to understand it - the languages of music

${ }^{9}$ Ludwig Wittgenstein, Tractatus Logico-Philosophicus [1921], trans. D. Pears and B. McGuinness (London: Routledge, 2001), $\S \S 4.1212,6.36$ \& 6.522.

10 Robert Root-Bernstein, 'The Sciences and Arts Share a Common Creative Aesthetic', in The Elusive Synthesis, ed. A.I. Tauber, A.I. (Dordrecht: Kluwer, 1997), pp. 49-82, here p. 53.

${ }^{11}$ We may sometimes feel, on the other hand, that there is such a thing as bad music well composed. But I think in such cases we usually mean that some aspect of the music (for example, the orchestration) is good, while other aspects are poor; or simply that the music is highly polished cliché.

12 It is also worth noting that moments of 'inspiration' in science or any other field are also not 'research', and any scientist whose main working method was quasi-artistic would probably meet with similar problems in specifying research plans and objectives. 
aesthetics, criticism and analysis, for instance - but these are far removed from the language of composition-as-research. On the one hand we have writing that attempts, however imperfectly, to articulate something about existing music, in all its complexity and ambiguity; on the other, we have a language aimed at shoehorning music - often music that does not yet exist - into an inappropriate category. Research about music that already exists is a real activity; composition-as-research is not. The most original things that happen in music are usually not 'ideas' had in advance, but striking or idiosyncratic musical solutions to problems of musical material that arise only during the process of composition. Beethoven is again a good example: we hear him composing himself into a corner, necessitating a radical way out of the resulting musical impasse. (Try putting something like that in your research grant application.)

Compositional originality is of a different order to that found in research. Notwithstanding the vast and tedious popular literature on 'creativity', which relentlessly insists that creativity is just about combining pre-existing ideas, the most original music, whatever its debt to the past, has a kind of waywardness or intransigence that has more to do with rejecting unwanted influences, or hermetically pursuing something that nobody else is interested in. In this is it the opposite of research - in general, a researcher cannot simply decide to ignore swathes of previous research because it suits her to do so, or cultivate a deliberate obliviousness to the scholarly context in which she works. But for a composer, this might be just the right thing to do.

It might be objected that the idea that composition is a kind of research, despite being strictly false, is still applicable in a looser, or even metaphorical, sense. But the value of an analogy or metaphor is surely in its utility - does it help our understanding, or provide a fruitful insight? So we have to ask: when a composer is working on a piece, is this work helped in any way by the thought that it is research, or the presentation of research 'findings'? While I find it hard to see this thought making much difference to any compositional decision, it's entirely possible that some composers might find it useful in some way. All kinds of things can be suggestive, after all - but that's precisely the point: equally suggestive might be the metaphor of composing as gardening, or alchemy, or fishing. The institutional imposition of the research metaphor is scarcely less perverse than would be the imposition of a gardening metaphor, and rather more destructive. It is a sign of the hollowed-out instrumentalism of academia today that the description of composition as research is seen as the achievement of some kind of status.

By reducing compositional quality and originality to forms of innovation amenable to the language of research, we completely lose sight of the former: the most radically original music for string quartet will be difficult if not impossible to describe in these terms, whereas the icecap-based internet improv project, while having the kind of 'originality' that can be documented and verified, may well yield music that is utterly conventional, or just not very good. Our concepts of musical value are grossly distorted by applying the wrong criteria. What is to be done? Many of us will be out of a job if we refuse to keep up the pretence. There is no reason to think that composition should not be studied in universities. A return to the older idea of 'research equivalence', while not without its problems, would be a step in the right direction. For now, the least we can do is to guard against actually believing in our research narratives, 
to be honest with students about the fact that 'research questions' don't really have anything to do with composition, and to insist on using a vocabulary appropriate to music even when under pressure to write in 'researchese'. Perhaps, given the direction of higher education more generally, this is the least of our worries, and we'll have to retreat to our garrets soon enough. 